\title{
RESEARCH
}

Open Access

\section{Educational inequalities in all-cause and cause-specific mortality among people with gout: a register-based matched cohort study in southern Sweden}

\author{
Ali Kiadaliri ${ }^{1,2,3^{*}}$ (D), Margarita Moreno-Betancur ${ }^{4,5}$, Aleksandra Turkiewicz ${ }^{1}$ and Martin Englund ${ }^{1,6}$
}

\begin{abstract}
Background: Gout is the most common inflammatory arthritis with a rising prevalence around the globe. While educational inequalities in incidence and prevalence of gout have been reported, no previous study investigated educational inequality in mortality among people with gout. The aim of this study was to assess absolute and relative educational inequalities in all-cause and cause-specific mortality among people with gout in comparison with an age- and sex-matched cohort free of gout in southern Sweden.

Methods: We identified all residents aged $\geq 30$ years of Skåne region with doctor-diagnosed gout (ICD-10 code M10, $n=24,877$ ) during 1998-2013 and up to 4 randomly selected age- and sex-matched comparators free of gout (reference cohort, $n=99,504$ ). These were followed until death, emigration, or end of 2014. We used additive hazards models and Cox regression adjusted for age, sex, marital status, and country of birth to estimate slope and relative indices of inequality (SII/RII). Three cause-of-death attribution approaches were considered for RII estimation: "underlying cause", "any mention", and "weighted multiple-cause".

Results: Gout patients with the lowest education had 1547 (95\% Cl: 1001, 2092) more deaths per 100,000 personyears compared with those with the highest education. These absolute inequalities were larger than in the reference population $(1255,95 \%$ Cl: 1038, 1472). While the contribution of cardiovascular (cancer) mortality to these absolute inequalities was greater (smaller) in men with gout than those without, the opposite was seen among women. Relative inequality in all-cause mortality was smaller in gout (RII $1.29[1.18,1.41]$ ) than in the reference population $(1.46[1.38,1.53])$. The weighted multiple-cause approach generally led to larger Rlls than the underlying cause approach.

Conclusions: Our register-based matched cohort study showed that low level of education was associated with increased mortality among gout patients. Although the magnitude of relative inequality was smaller in people with gout compared with those without, the absolute inequalities were greater reflecting a major mortality burden among those with lower education.
\end{abstract}

Keywords: Education, Inequality, Gout, Cause-specific mortality, Multiple cause of death, Sweden

\footnotetext{
* Correspondence: aliasghar.ahmad_kiadaliri@med.lu.se

${ }^{1}$ Faculty of Medicine, Department of Clinical Sciences Lund, Orthopaedics,

Clinical Epidemiology Unit, Lund University, Lund, Sweden

${ }^{2}$ Centre for Economic Demography, Lund University, Lund, Sweden

Full list of author information is available at the end of the article
}

(c) The Author(s). 2019 Open Access This article is distributed under the terms of the Creative Commons Attribution 4.0 International License (http://creativecommons.org/licenses/by/4.0/), which permits unrestricted use, distribution, and reproduction in any medium, provided you give appropriate credit to the original author(s) and the source, provide a link to the Creative Commons license, and indicate if changes were made. The Creative Commons Public Domain Dedication waiver (http://creativecommons.org/publicdomain/zero/1.0/) applies to the data made available in this article, unless otherwise stated. 


\section{Background}

Gout is the most common inflammatory arthritis with a rising prevalence around the globe [1]. Previous studies estimated a prevalence range of $0.6 \%-1.8 \%$ and incidence of 16-24 cases per 10,000 person-years for gout in Sweden [2-4]. In addition, Sweden had the 15th highest rate of years lived with disability for gout among 195 countries in 2015 [5]. In addition to causing pain, joint damage, functional impairment, and reduced healthrelated quality of life, gout is associated with increased mortality [1, 6-8]. A recent study in southern Sweden reported a $17 \%$ higher hazard of all-cause mortality among persons with gout than those without gout [8]. Socioeconomic status (SES) including education is a well-documented predictor of health outcomes including mortality. According to the framework proposed by the World Health Organization (WHO) Commission on Social Determinants of Health, SES is considered as a "structural determinant" of health inequalities that through a set of "intermediary determinants" (material circumstances, psychosocial circumstances, behavioural and/or biological factors, and the health system itself) influences exposure and vulnerability to health-compromising conditions [9]. While very few studies assessed associations between SES and incidence and prevalence of gout $[4,10-12]$, to our knowledge, no previous study investigated association between SES and mortality among people with gout. Assessing educational inequalities in cause-specific mortality provides valuable information to identify major causes responsible for inequalities in mortality. To address this, we assessed the absolute and relative educational inequalities in allcause and cause-specific mortality among people with gout in comparison with a randomly selected age- and sex matched cohort without gout in southern Sweden.

\section{Material and method}

\section{Study setting and design}

We conducted an observational register-based matched cohort study. The study was conducted in the southernmost region of Sweden, Skåne, with a population of about 1.3 million in 2014 (13.2\% of the Sweden's population).

\section{Study population}

Using the Skåne Health Care Register and the Swedish Population Register, we identified all residents aged $\geq 30$ years who had been diagnosed with gout (the International Classification of Diseases, 10th revision [ICD-10] code M10) by a physician (within primary or secondary care) between 1 January 1998 and 31 December 2013. The date of the first diagnosis of gout was considered as the index date. From the population at risk (i.e. those without a gout diagnosis), we randomly selected up to four comparators free of gout matched by age and sex to each person with gout (the reference cohort). These comparators received the same index date as their gout matched subject. These data were linked with other registers using the personal identification number assigned to all residents in Sweden.

Level of education and socio-demographic characteristics We acquired the data on level of education, marital status, and country of birth from the Longitudinal Integration Database for Health Insurance and Labour Market Studies (LISA). We divided the highest level of attained education into three categories: "low" (0-9 years of education), "medium" (10-12 years of education), and "high" ( $>12$ years of education).

\section{Outcome and follow-up}

The individual-level data on all death certificates issued in the region during 1998-2014 were obtained from the Swedish National Board of Health and Welfare's Cause of Death Register (http://www.socialstyrelsen.se/). We extracted date of death, the underlying cause of death (UCD), and contributory causes of death according to the ICD-10 from these death certificates. Based on the ICD-10 system, we defined nine main groups of causes of death (infectious diseases, neoplasms, blood \& endocrine diseases, mental and nervous diseases, cardiovascular diseases, respiratory diseases, digestive diseases, genitourinary diseases, and other causes). We used the underlying cause of death (UCD) to identify cause-specific deaths in our main analysis, and contributory causes in sensitivity analyses.

Each subject's follow-up started at the index date or his/her 30th birthday whichever occurred last. All subjects were followed until death, relocation outside Skåne, or end of 2014, whichever occurred first. It should be noted that the exposure ascertainment period was 19982013 and the subjects were followed until the end of 2014, to ensure that each included person would have at least one year of observation period.

\section{Statistical analysis}

We assessed relative educational inequalities by estimating the relative index of inequality (RII) - defined as the log-linear association between educational level and mortality, and roughly speaking can be interpreted as the ratio of mortality rates between the two extremes of the educational hierarchy. To estimate RII, each level of education was assigned a fractional rank based on the mean proportion of the population with a higher level of education [13]. Therefore fractional rank is a continuous variable ranging from 0 (the highest education) to 1 (the lowest education). The RII was estimated using causespecific Cox proportional hazard models [14]. The fractional rank was included as a covariate in these models 
and the exponential of its coefficient provides an estimate of RII.

We measured the absolute educational inequality by estimating the slope index of inequality (SII) - defined as the linear association between educational level and mortality, and roughly speaking can be interpreted as the absolute difference in mortality rates between the two extremes of the educational hierarchy. The SII was estimated by fitting cause-specific additive hazard model where the coefficient of the fractional rank provides an estimate of SII [13]. The contribution of a specific cause of death to the absolute educational inequality in allcause mortality was estimated by dividing the SII of that cause by the SII of all-cause mortality.

In all models time since study entry was used as the timescale and all models were adjusted for age (as continuous variable), sex, marital status (never married, previously married, and married), and country of birth (Sweden-born vs. non-Sweden born). Separate models were estimated for those with and without gout. Subgroup analyses by sex and age group (30-74 years, and $\geq$ 75 years) were also conducted. Analyses were performed using Stata version 15 (data preparation and estimating RIIs for main analysis) and RStudio version 1.1.423 (estimating RIIs for sensitivity analysis using "survMCOD" package, and SIIs using "timereg" package).

\section{Sensitivity analysis}

In an era characterized by aging population and rising prevalence of multi-morbidity, the UCD might not adequately capture mortality associated with a specific cause [15]. To account for this, we followed two alternative approaches [15] as sensitivity analysis in estimating the causespecific RIIs: 1) "any mention" approach, where a death with mention of the cause on any part of the death certificate is considered as an event in the Cox models, and 2) "weighted multiple-cause" model, which is an extension of the competing risks Cox model for multiple-cause mortality. This approach requires assigning a positive weight to each cause mentioned on the death certificate such that the sum of the weights per death certificate is equal to one. We considered three weighting strategies: a) equal weights $(1 /$ number of causes on a death certificate), b) a weight of 0.5 to the UCD and equal weights to non-underlying causes $(0.5 /$ number of non-underlying causes), c) a weight of 0.75 to the UCD and equal weights to non-underlying causes $(0.25 /$ number of non-underlying causes). While in the "any mention" approach a death where the certificate mentions more than one cause would be counted as multiple deaths, the "multiple cause of death" approach does not suffer from this limitation. The "any mention" approach has been shown in simulation studies to underestimate standard errors, leading to invalid $p$-values (too low) and confidence intervals (too narrow, with poor coverage probabilities) [15].

\section{Results}

A total of 24,877 patients with a doctor-diagnosed gout during 1998-2013 were identified. We identified 99,504 age- and sex-matched individuals without gout as the reference population (1 patient had no comparator). After exclusion of 842 (3.4\%) individuals with missing level of education, we observed 8133 deaths during 127,910 person-years follow up among gout patients (Table 1). In the reference population, we excluded 1670 (1.7\%) who did not enter the study (died or emigrated prior to the index date), 3457 (3.5\%) with missing data on level of education, and 6 with missing on country of birth. There were 24,051 deaths over 554,054 person-years follow up in the reference population included in the study. In both groups, those with low level of education constituted the largest portion of the sample $(45.1 \%$ in gout patients vs. $40.2 \%$ in the reference population). Cardiovascular diseases (CVDs) accounted for $50.3 \%$ of the causes of deaths among people with gout versus $41.2 \%$ in the reference population (Supplementary Fig. S1). On the other hand, neoplasms constituted $18.4 \%$ of deaths among gout patients versus $24.5 \%$ in the reference cohort.

The RII showed that all-cause mortality rate in the low educated gout patients was 1.3 (95\% CI: 1.2, 1.4) times higher than the highly educated ones (Table 2). These educational inequalities persisted across sex and age subgroups. For CVDs as the leading cause of death, the RII was 1.4 (95\% CI: 1.2, 1.6). Across remaining causes of death, the RII ranged from 0.89 (95\% CI: $0.58,1.38)$ for mental and nervous diseases to $1.65(1.07,2.55)$ for blood and endocrine diseases. The magnitude of RII in all-cause mortality among gout patients was smaller than in the reference population (Table 3). The similar pattern was seen across subgroups except women who had almost identical RIIs regardless of their gout status.

The SII revealed that there were, on average, 1547 (95\% CI: 1001, 2092) more deaths per 100,000 person-years in the least vs. most educated gout patients. CVDs made the largest contribution (64\%) to this difference, followed by neoplasms (12.7\%) and blood\& endocrine diseases (8.5\%, Fig. 1). The magnitude of absolute educational inequality in allcause mortality was greater in people with gout compared with those without (SII 1255 per 100,000 person-years, 95\% CI: 1038,1472$)$. The contributions of CVDs ( $64 \%$ vs. $54 \%)$, blood \& endocrine diseases ( $8.5 \%$ vs. $2.2 \%$ ), and genitourinary diseases $(5.0 \%$ vs. $1.1 \%)$ to the absolute inequalities in all-cause mortality were more pronounced in gout patients than in the reference population. While among people with gout, the absolute educational inequality in all-cause mortality was greater in women than men (2052 vs. 1411 deaths per 100,000 person-years), the opposite was observed among those without gout (1139 vs. 1320 deaths per 100,000 person-years). In both groups, the SIIs were larger in people aged $\geq 75$ years than younger ones. There were variations by 
Table 1 Baseline characteristics of participants and the number of all-cause and cause-specific deaths, stratified by sex

\begin{tabular}{|c|c|c|c|c|}
\hline & \multicolumn{2}{|c|}{ Gout patients } & \multicolumn{2}{|c|}{ The reference population } \\
\hline & Women & Men & Women & Men \\
\hline N (\%) & $7431(30.9)$ & $16,604(69.1)$ & $29,258(31.0)$ & $65,113(69.0)$ \\
\hline \multicolumn{5}{|l|}{ Age at entry (years), \% } \\
\hline $30-49$ & 6.9 & 13.9 & 6.9 & 13.9 \\
\hline $50-64$ & 16.3 & 26.9 & 16.7 & 27.3 \\
\hline $65-79$ & 39.1 & 39.7 & 39.7 & 39.9 \\
\hline $80+$ & 37.7 & 19.5 & 36.7 & 18.9 \\
\hline \multicolumn{5}{|l|}{ Level of education, \% } \\
\hline Low (0-9years of education) & 54.7 & 40.8 & 46.9 & 37.1 \\
\hline Medium (10-12 years of education) & 33.6 & 40.2 & 35.1 & 39.2 \\
\hline High (> 12 years of education) & 11.7 & 19.0 & 18.0 & 23.7 \\
\hline \multicolumn{5}{|l|}{ Marital status at entry, \% } \\
\hline Never married & 6.8 & 12.7 & 8.8 & 15.3 \\
\hline Previously married & 52.7 & 23.7 & 48.2 & 22.4 \\
\hline Married & 40.5 & 63.5 & 43.0 & 62.3 \\
\hline Born in Sweden, \% & 88.4 & 88.3 & 88.4 & 86.9 \\
\hline Total deaths (\%) & $2961(100)$ & $5172(100)$ & $8525(100)$ & $15,526(100)$ \\
\hline Infectious diseases (\%) & $98(3.3)$ & $133(2.6)$ & $194(2.3)$ & $348(2.2)$ \\
\hline Neoplasms (\%) & $438(14.8)$ & $1057(20.4)$ & $1645(19.3)$ & $4247(27.4)$ \\
\hline Blood \& endocrine diseases (\%) & $146(4.9)$ & $219(4.2)$ & $244(2.9)$ & $459(3.0)$ \\
\hline Mental \& nervous diseases (\%) & $146(4.9)$ & $191(3.7)$ & $1043(12.2)$ & $1166(7.5)$ \\
\hline Cardiovascular diseases (\%) & $1509(51.0)$ & $2581(49.9)$ & $3681(43.2)$ & $6228(40.1)$ \\
\hline Respiratory diseases (\%) & $220(7.4)$ & $324(6.3)$ & $574(6.7)$ & $1209(7.8)$ \\
\hline Digestive diseases (\%) & $106(3.6)$ & $191(3.7)$ & $261(3.1)$ & $469(3.0)$ \\
\hline Genitourinary diseases (\%) & $92(3.1)$ & $140(2.7)$ & $122(1.4)$ & $257(1.7)$ \\
\hline Other causes (\%) & $206(7.0)$ & $336(6.5)$ & $761(8.9)$ & $1143(7.4)$ \\
\hline Person-years follow-up & 36,488 & 91,422 & 165,910 & 388,117 \\
\hline
\end{tabular}

age, sex, cause, and gout status in the patterns of absolute educational inequalities and contributions of causes of death to these inequalities. For instance, in both groups, neoplasms had a substantially larger contribution to the absolute educational inequalities in all-cause mortality among younger people compared with those older.

The magnitude of relative inequalities were generally greater using the "weighted multiple-cause" approach compared with the UCD approach (further distance from 1). Furthermore, in contrast with the UCD approach, the "weighted multiple-cause" approach did not evidence an inverse association between education and cause-specific mortality for infectious diseases, digestive diseases, and other causes among gout patients. As expected, the "any mention" approach resulted in narrower 95\% CIs for RIIs (Table 4).

\section{Discussion}

In this study, for the first time, we quantified the absolute and relative educational inequalities in all-cause and cause-specific mortality in gout patients and contrasted these with the estimates from a randomly selected ageand sex matched cohort free of gout. Our results suggested that while the magnitude of relative educational inequalities were smaller in gout patients compared with the reference population, the former experienced greater degree of the absolute educational inequalities reflecting a larger mortality burden. Although CVDs were the main driver of absolute educational inequalities in both groups, their relative importance was more pronounced in gout patients than in the reference population. The strengths of associations between level of education and mortality varied by cause of death and its attribution approach, sex, as well as age.

Previous studies have relatively consistently shown that people with lower SES have higher incidence and prevalence of gout $[4,10,11]$, suffer from more severe gout [16], and are more prone to discontinue therapy [17]. In our sample, gout patients were, on average, less educated 


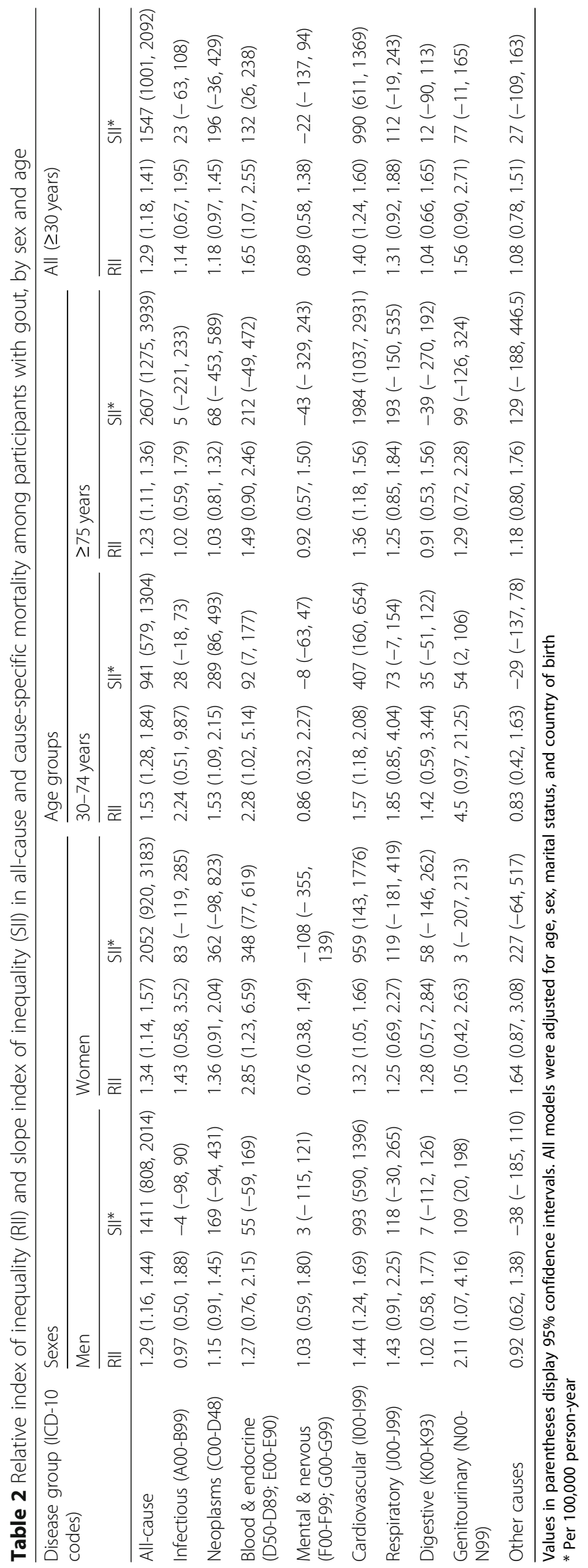




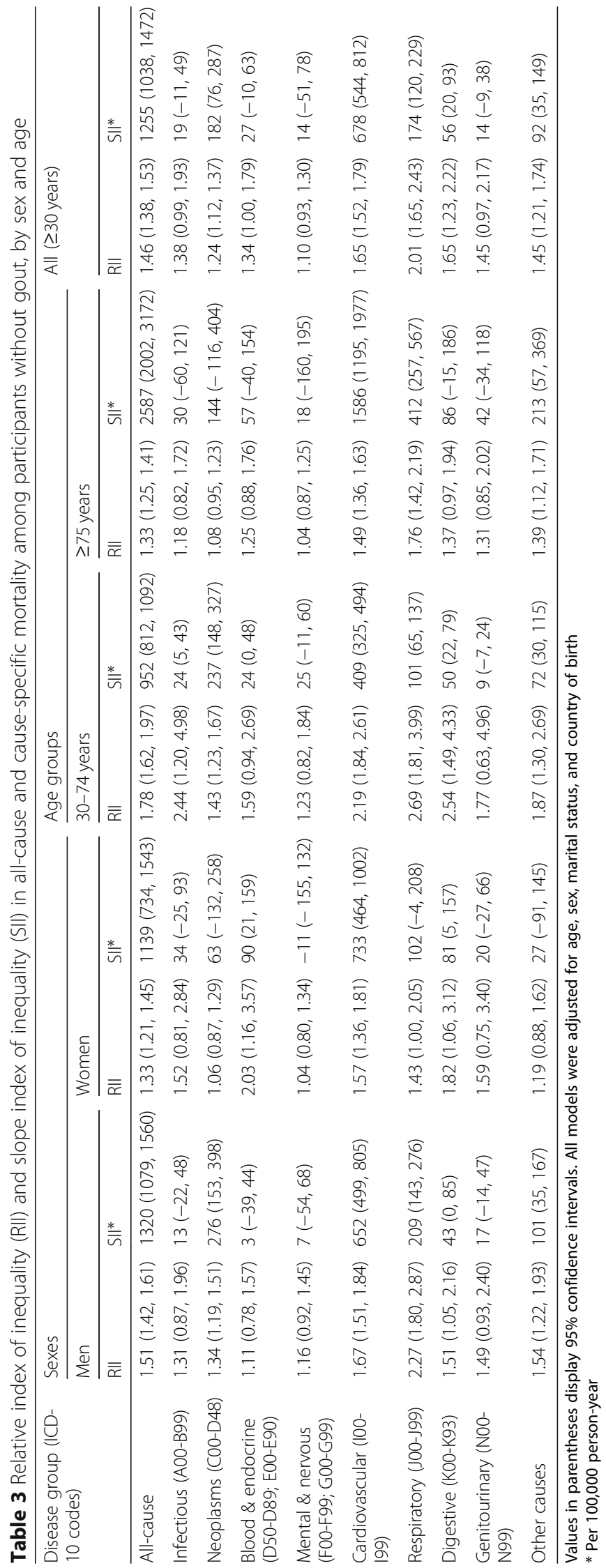




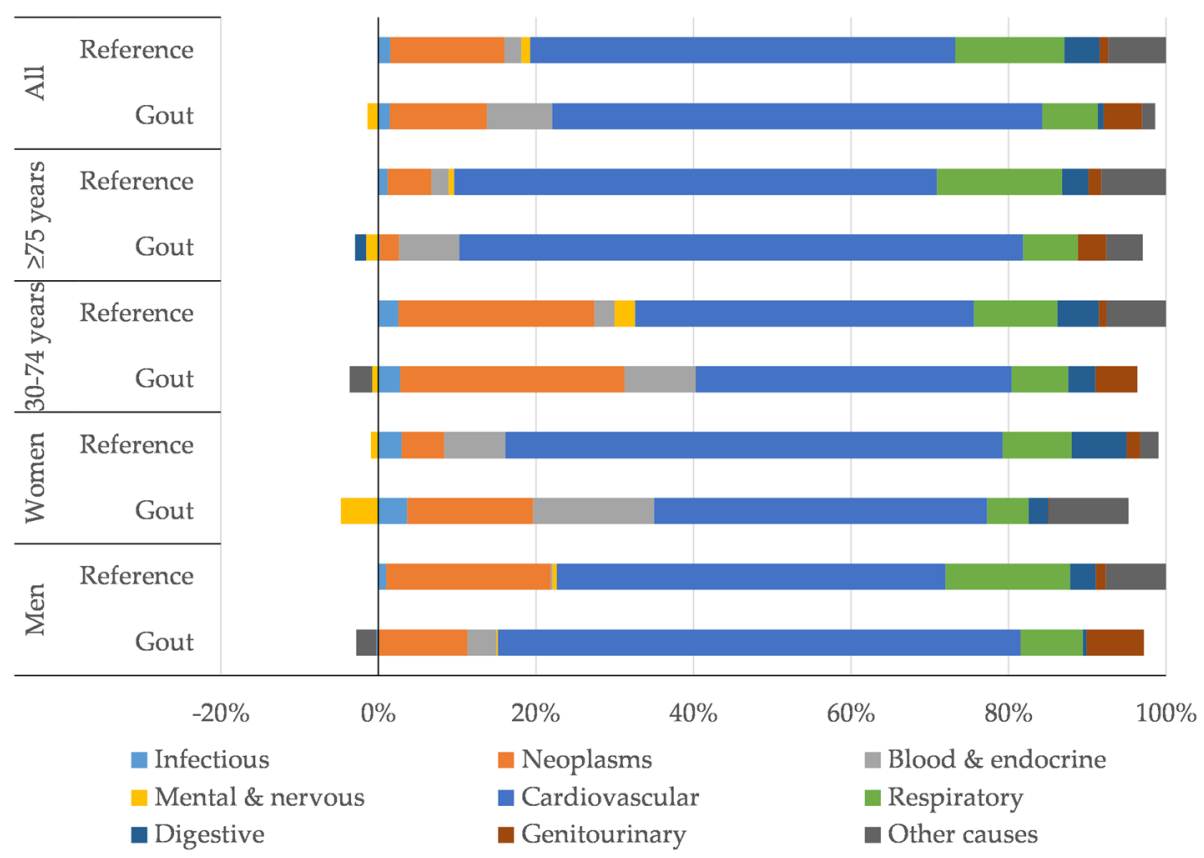

Fig. 1 Contribution of specific causes of death to the absolute inequality in all-cause mortality

than their non-gout comparators. In addition, higher prevalence of unhealthy behaviours (e.g. alcohol consumption, smoking, physical inactivity) and multi-morbidity among low educated people might partially explain the observed inequalities in our study $[18,19]$. Furthermore, despite universal healthcare access in Sweden, educational differences in healthcare utilisation should not be overlooked.

Our results revealed that the magnitude of relative educational inequalities were less pronounced in people with gout than those without. While underlying pathways for this finding need further investigation, one potential explanation is that contacts with healthcare service might decline educational inequalities in health and mortality risk among patients with gout. In contrast, the magnitude of absolute educational inequality in allcause mortality was larger in gout patients than in the reference population. This finding is mainly driven by larger absolute inequalities in deaths from CVDs and blood \& endocrine diseases in gout patients compared with the reference population. Smaller relative inequalities and larger absolute inequalities in a disease group compared with those without the disease has previously been reported $[20,21]$. This finding highlights the importance of assessing both relative and absolute inequalities in presenting an accurate picture of socioeconomic inequalities in health.

The substantial contribution of CVDs to the absolute inequalities in all-cause mortality highlights the need for improved prevention and treatment of these diseases among gout patients with lower education, particularly considering that gout patients have a higher CVDs mortality rate than those without gout [6]. The contribution of CVDs to the absolute inequalities in all-cause mortality rose with age while the opposite was observed for neoplasms. Similar patterns have been observed in the reference population in our study and also in the general population in other countries and have been attributed to reduction in socioeconomic differences in the prevalence of risk factors for cancer (e.g. smoking) with increasing age [22].

Quantifying, for the first time, both absolute and relative educational inequalities in all-cause and several cause-specific mortality in a large cohort of gout patients and comparing it with those without gout are the main strengths of the current study. Furthermore, we applied the recent methodology advances in studying SII [13] and multiple-cause of death data [15]. Despite these, several limitations of the current study should be acknowledged. We studied only gout patients diagnosed by a physician and possibility of misdiagnosis and occasional coding errors cannot be ruled out, but is expected to be non-differential. While Sweden has a high quality cause of death register [23], death certificates are subject to misclassification including over-reporting of some causes (e.g. CVDs). If there are educational differences in quality of cause of death data, then our estimates would be biased. However, a previous study found no educational differences in the use of ill-defined causes of death in Sweden [24]. Due to the lack of data, we did not control 


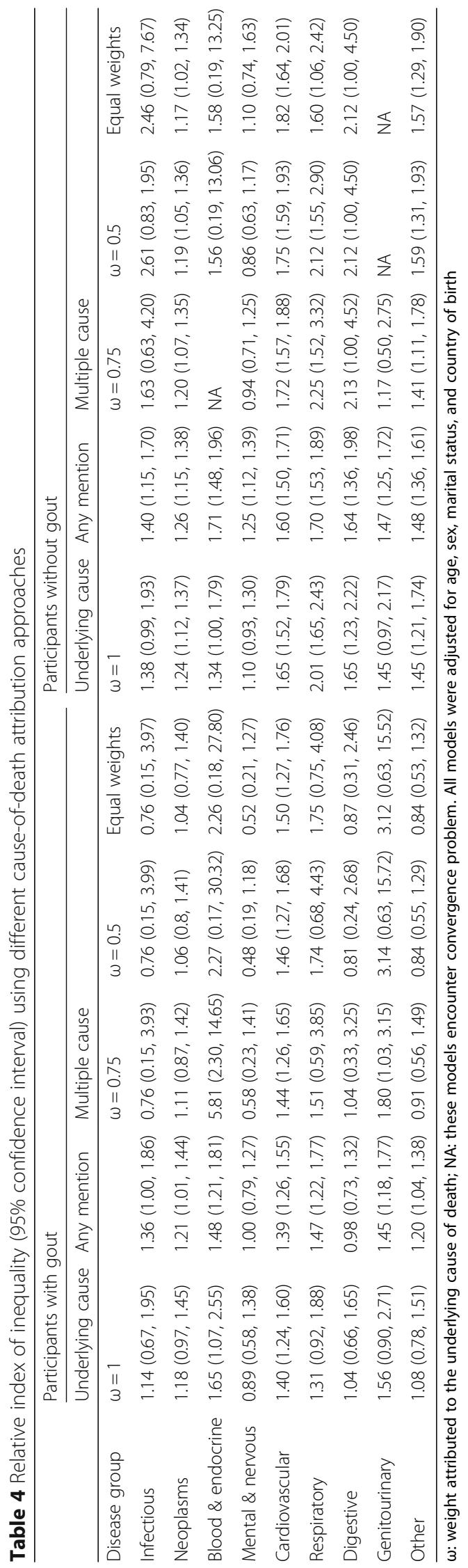


for several important confounders of the educationmortality or (age at diagnosis of) gout-mortality associations, which could lead to confounding or selection bias, respectively. These include, for instance, cognitive ability, family background, body mass index, and early life health status. This suggests that no causal inference should be made from the findings. It also should be noted that the reference cohort in our study included age-and sex-matched comparators free of gout which might not be representative of the general population and hence any extrapolation of the results to the general population should be avoided.

\section{Conclusion}

Our study showed that low level of education was associated with increased mortality among gout patients. Although the magnitude of relative inequality was smaller in people with gout than in the reference cohort, the absolute inequality was larger in those with gout reflecting a major mortality burden among those with lower education, especially low educated women. The strength of these associations varied by cause of death and its attribution approach, sex, and age. Our results call for improvements in management of gout and comorbidities in Sweden. In particular, decreasing exposure to CVDs risk factors through implementing effective interventions for all, with greater intensity for low educated individuals, should be a public health priority.

\section{Supplementary information}

Supplementary information accompanies this paper at https://doi.org/10. 1186/s12939-019-1076-1.

Additional file 1: Fig. S1. The distribution of causes of death in the whole sample and across education groups.

\section{Abbreviations}

Cl: Confidence interval; CVDs: Cardiovascular diseases; Rll: Relative index of inequality; SES: Socioeconomic status; SII: Slope index of inequality: UCD: Underlying cause of death

\section{Acknowledgements}

Not applicable.

\section{Authors' contributions}

AK participated in the design, analysis, and interpretation of results and drafting the manuscript. MMB participated in analysis, and interpretation of results, and revision of the manuscript for important intellectual content. AT and ME participated in acquisition of data, interpretation of results, and revision of the manuscript for important intellectual content. All authors approved the final manuscript.

\section{Funding}

This work was supported by grants from Greta and Johan Kock Foundations; The Swedish Research Council; The Swedish Rheumatism Association; Österlund Foundation; and Clinical Research within National Health Services (ALF).

Availability of data and materials

No additional data is available.

\section{Ethics approval and consent to participate}

All procedures performed in the study were in accordance with the 1964 Helsinki declaration and its later amendments and all aspects of the study including access and use the data was approved by the Lund University Ethics committee (Dnr 2014/276). The need for individual informed consent was waived by the Ethics committee. The study was advertised in the major newspapers where a possibility to opt-out was offered. This is a principle used in Sweden for population-wide studies using non-identifiable register data (http://www.codex.vr.se/en/manniska6.shtml).

\section{Consent for publication}

Not applicable.

\section{Competing interests}

AK is an associate editor of BMC Musculoskeletal Disorders. The other authors declare that they have no conflict of interest

\section{Author details}

${ }^{1}$ Faculty of Medicine, Department of Clinical Sciences Lund, Orthopaedics, Clinical Epidemiology Unit, Lund University, Lund, Sweden. ${ }^{2}$ Centre for Economic Demography, Lund University, Lund, Sweden. ${ }^{3}$ Skåne University Hospital, Clinical Epidemiology Unit, Remissgatan 4, SE-221 85 Lund, Sweden. ${ }^{4}$ Clinical Epidemiology and Biostatistics Unit, Murdoch Children's Research Institute, Melbourne, Australia. ${ }^{5}$ Centre for Epidemiology and Biostatistics, Melbourne School of Population and Global Health, University of Melbourne, Melbourne, Australia. ${ }^{6}$ Clinical Epidemiology Research and Training Unit, Boston University School of Medicine, Boston, MA, USA.

Received: 13 May 2019 Accepted: 11 October 2019

Published online: 28 October 2019

\section{References}

1. Shields GE, Beard SM. A systematic review of the economic and humanistic burden of gout. Pharmacoeconomics. 2015;33:1029-47.

2. Wandell $P$, Carlsson AC, Ljunggren G. Gout and its comorbidities in the total population of Stockholm. Prev Med. 2015;81:387-91.

3. Dehlin M, Drivelegka P, Sigurdardottir V, Svard A, Jacobsson LT. Incidence and prevalence of gout in Western Sweden. Arthritis Res Ther. 2016;18:164

4. Kapetanovic MC, Hameed M, Turkiewicz A, Neogi T, Saxne T, Jacobsson L, et al. Prevalence and incidence of gout in southern Sweden from the socioeconomic perspective. RMD Open. 2016;2:e000326.

5. Kiadaliri AA, Uhlig T, Englund M. Burden of gout in the Nordic region, 19902015: findings from the global burden of disease study 2015. Scand J Rheumatol. 2018:47:410-7.

6. Clarson LE, Chandratre P, Hider SL, Belcher J, Heneghan C, Roddy E, et al. Increased cardiovascular mortality associated with gout: a systematic review and meta-analysis. Eur J Prev Cardiol. 2015;22:335-43.

7. Fisher MC, Rai SK, Lu N, Zhang Y, Choi HK. The unclosing premature mortality gap in gout: a general population-based study. Ann Rheum Dis. 2017;76:1289-94.

8. Vargas-Santos AB, Neogi T, da Rocha C-PG, Kapetanovic MC, Turkiewicz A. Cause-specific mortality in gout: novel findings of elevated risk of noncardiovascular related deaths. Arthritis Rheumatol. 2019. https://doi.org/10. 1002/art.41008.

9. Solar O, Irwin A. A conceptual framework for action on the social determinants of health. Geneva, Switzerland: WHO; 2010.

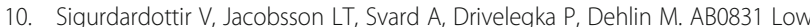
Education Level as A Predictor of Gout in Western Sweden. Ann Rheum Dis. 2016:75:1187-8.

11. Hayward RA, Rathod T, Roddy E, Muller S, Hider SL, Mallen CD. The association of gout with socioeconomic status in primary care: a crosssectional observational study. Rheumatology (Oxford). 2013;52:2004-8.

12. Taylor W, Smeets L, Hall J, McPherson K. The burden of rheumatic disorders in general practice: consultation rates for rheumatic disease and the relationship to age, ethnicity, and small-area deprivation. N Z Med J. 2004; 117:U1098.

13. Moreno-Betancur M, Latouche A, Menvielle G, Kunst AE, Rey G. Relative index of inequality and slope index of inequality: a structured regression framework for estimation. Epidemiology. 2015;26:518-27.

14. Putter H, Fiocco M, Geskus RB. Tutorial in biostatistics: competing risks and multi-state models. Stat Med. 2007;26:2389-430. 
15. Moreno-Betancur M, Sadaoui H, Piffaretti C, Rey G. Survival analysis with multiple causes of death: extending the competing risks model. Epidemiology. 2017;28:12-9.

16. Pillinger M, Krasnokutsky SS, Malamet R, Schechter B, Taylor DC, Morlock R. Relationship between patient and disease factors and severity of gout in a real-world population [abstract]. Arthritis Rheumatol. 2016; 68(suppl 10).

17. Zandman-Goddard G, Amital H, Shamrayevsky N, Raz R, Shalev V, Chodick G. Rates of adherence and persistence with allopurinol therapy among gout patients in Israel. Rheumatology (Oxford). 2013;52:1126-31.

18. Syden $L$, Landberg J. The contribution of alcohol use and other lifestyle factors to socioeconomic differences in all-cause mortality in a Swedish cohort. Drug Alcohol Rev. 2017;36:691-700.

19. Pathirana $\mathrm{TI}$, Jackson CA. Socioeconomic status and multimorbidity: a systematic review and meta-analysis. Aust N Z J Public Health. 2018;42:186-94.

20. Gnavi R, Petrelli A, Demaria M, Spadea T, Carta Q, Costa G. Mortality and educational level among diabetic and non-diabetic population in the Turin longitudinal study: a 9-year follow-up. Int J Epidemiol. 2004;33(4):864-71.

21. Dray-Spira R, Gary-Webb TL, Brancati FL. Educational disparities in mortality among adults with diabetes in the U.S. Diabetes Care. 2010;33(6):1200-5.

22. Huisman M, Kunst AE, Bopp M, Borgan JK, Borrell C, Costa G, et al. Educational inequalities in cause-specific mortality in middle-aged and older men and women in eight western European populations. Lancet. 2005;365:493-500.

23. Brooke HL, Talback M, Hornblad J, Johansson LA, Ludvigsson JF, Druid H, et al. The Swedish cause of death register. Eur J Epidemiol. 2017;32:765-73.

24. Kulhanova I, Menvielle G, Bopp M, Borrell C, Deboosere P, Eikemo TA, et al. Socioeconomic differences in the use of ill-defined causes of death in 16 European countries. BMC Public Health. 2014;14:1295.

\section{Publisher's Note}

Springer Nature remains neutral with regard to jurisdictional claims in published maps and institutional affiliations.

Ready to submit your research? Choose BMC and benefit from:

- fast, convenient online submission

- thorough peer review by experienced researchers in your field

- rapid publication on acceptance

- support for research data, including large and complex data types

- gold Open Access which fosters wider collaboration and increased citations

- maximum visibility for your research: over $100 \mathrm{M}$ website views per year

At $\mathrm{BMC}$, research is always in progress.

Learn more biomedcentral.com/submissions 